\title{
EFFECT OF COBALT CHLORIDE ON THE OXYGEN CONSUMPTION AND VENTILATION RATE OF A FRESHWATER FISH, CIRRHINUS MRIGALA (HAM)
}

\author{
Rachana Kumari ${ }^{1}$, Shahi R. N. P $^{2}$ \\ ${ }^{1}$ Department of Biotechnology, Amity Institute of Biotechnology, Amity University, Noida, Uttar Pradesh, India \\ ${ }^{2}$ Department of Zoology, L. N. T. College (B.R.A.B.U.), Muzaffarpur, Bihar, India
}

\begin{abstract}
The fish Cirrhinus mrigala (Ham.) exposed to lethal and sublethal concentrations of cobalt chloride at selected periods showed a decrease in their ventilation rate up to $27.91 \%$ in lethal concentration at $240 \mathrm{hr}$ of exposure, while, in sublethal concentrations initially increased up to 23.95 \& $27.91 \%$ at 96 and $240 \mathrm{hr}$ of exposure followed by a decline up to 24.70 and $12.94 \%$ at $960 \mathrm{hr}$ of exposure to 39.45 and $13.10 \mathrm{mg} / \mathrm{l}$ concentration respectively. The $\mathrm{O}_{2}$ uptake rate initially increased followed by a decline up to $54.47 \%$ at $240 \mathrm{hr}$ of exposure to lethal concentration $(92.00 \mathrm{mg} / \mathrm{l})$ \& up to 28.80 \& $10.65 \%$ in sublethal concentration at $960 \mathrm{hr}$ of exposure.
\end{abstract}

Keywords: $\mathrm{O}_{2}$ uptake; ventilation rate: Cirrhinus mrigala; Cobalt chloride

$* * *$

\section{INTRODUCTION}

Oxygen consumption rate in fish has been considered as an index for denoting the intensity of metabolism (fry, 1957, 1971). The metabolic activity of an organism is increased by its oxygen utilization and so it becomes possible to determine "no stress" effect of any toxicant on the organism if we know oxygen-utilization rate of that particular organism. Changes in the respiratory behavior and metabolic rate of pollutant induced fish have drawn the attention of several biologists, (Singh \& Singh, 1979; Roy \& Munshi, 1988; Sastry \& Shukla, 1990; and Kumar, 1999), but their results are conflicting as some have reported increased gill ventilation and decreased $\mathrm{O}_{2}$-uptake rate (Singh \& Singh, 1979 and Roy \& Munshi, 1988) while others have reported an increase in $\mathrm{O}_{2}$-uptake rate (Anderson et. al., 1974 and Natrajan \& Rajulu, 1983). As far cobalt is concerned, Vitamin B12 (Cobalbamin) contains 4\% cobalt and as little as $3 \mu \mathrm{g} /$ day controls pernicious anemia in man. Its toxicity is low but large amount may cause polycythemia. On the whole, cobalt is a potential metal pollutant but its effect on aquatic organisms especially fish is not yet fully known.

Hence, the present study, was conducted with an objective to evaluate the effect of different concentrations of cobalt chloride on ventilation rate $\&$ oxygen consumption of a major carp, Cirrhinus mrigala (Ham.) at selected periods.

\section{MATERIALS AND METHODS}

Healthy and living specimens of Cirrhinus mrigala(Ham.) of $24.6 \pm 3.2 \mathrm{gm}$ weight groups were procured from local fish-farm and brought to the laboratory in large buckets containing water of the same pond. The fish were bathed for 10-15 minutes in potassium permanganate solution $(0.1 \%)$ followed by several changes of ground water and then transferred to large aquaria / tubs containing ground water. They were acclimatized in the laboratory for 10-15 days. During this period and also during experiments, they were provided artificial food prepared in the laboratory following the method of Suraj (1995). The food was provided daily at least three hours prior to change of water / toxicant solution. The aquaria / Tub were provided aerator to maintain oxygen level of the water.

Stock solution of cobalt chloride (BDH reagent grade) were prepared by diluting a known quantity of chemical in $500 \mathrm{ml}$ distilled water as described in "Standard Method" APHA (1985). One or two drops of $\mathrm{HCl}$ was mixed in the water containing the metallic salt to prevent the formation of precipitate. Same amount of HCL was also mixed in water used for control experiment.

Lc50 value for $24,48,72 \& 96 \mathrm{hr}$ was determined as described by Dandoroff et. al.(1951) and APHA (1985), which were recorded to be 293.22, 219.96, 172.48 and $131.51 \mathrm{mg} / \mathrm{l} \mathrm{CoCl}$. Therefore, to study the effect of lethal and sublethal concentrations, $0.7 \mathrm{th}, 0.3 \mathrm{rd} \& 0.1 \mathrm{st}$ of $96 \mathrm{hr}$ Lc50 value were taken, which were $92.00,39.45$ and $13.10 \mathrm{mg} / \mathrm{l}$ respectively. 
Sufficient number of fish was exposed to each selected concentrations along with control. The oxygen consumption rate of five fish in normal and toxicant induced concentrations was measured in a continuous flow glass respirometer at 8,96 , 240,480 and $960 \mathrm{hr}$ of exposures. The ventilation rate of the fish were counted by visual observation of the opercular movements with the help of magnifying glass for 5 minutes at the time of $\mathrm{O} 2$ consumption reading and average value per fish per minute was calculated. For measuring the Oxygen consumption rate of fish, Winkler's iodemetric method (APHA, 1985) was followed to measure dissolved oxygen content in water.

\section{RESULTS}

Exposure to cobalt chloride water excites the fish and it started a frantic effort to come out of container and became aggressive for first few hours followed by inactiveness for some time, perhaps due to hyper-activity, difficulties in respiration as indicated by frequent surfacing to engulp air, loss of equilibrium, uncoordinated movements of the body musculature and titanic extension of jaw followed by turned over and laid floating either on the surface or on the bottom of the water with highly decreased opercular frequency depended on concentration and exposure period and abnormal secretion of mucus all over the body surface at the time of death.

The result of the experiments set up i.e. ventilation rate /minute and oxygen consumption rate (VO2: $\mathrm{mlO} / \mathrm{hr}$ and $\mathrm{mlO} 2 / \mathrm{Kg} / \mathrm{hr} / \mathrm{fish}$ ) are tabulated in Table -1 , which contains the average value of five fish exposed to $92.00,39.45 \& 13.10$ $\mathrm{mg} / \mathrm{l}$ cobalt chloride along with control for $8,24,96,240,480$ and $960 \mathrm{hr}$ of exposures.

The fish exposed to lethal concentration $(92.00 \mathrm{mg} / \mathrm{l})$ showed a gradual decrease in ventilation rate as the decline was significantly decreased at $24 \mathrm{hr}$ onward with maximum decline $(\mathrm{P}<0.01)$ up to $27.1 \%$ at $240 \mathrm{hr}$ of exposure, whereas, the fish exposed to sublethal concentrations $(39.45 \& 13.10$ $\mathrm{mg} / \mathrm{l})$ a significant increase was observed at $96 \& 240 \mathrm{hr}$ of exposure respectively, followed by a decline $(\mathrm{P}<0.01$ \& $<0.05)$ up to $27.40 \& 12.94 \%$ respectively at $960 \mathrm{hr}$ of exposure when compared with that of their normal values.

The fish exposed to $92.00 \mathrm{mg} / \mathrm{l}$ cobalt chloride, initially showed an increased oxygen consumption rate up to $12.65 \%$ at $8 \mathrm{hr}$ of exposure, followed by a gradual decrease which was found statistically significant $(\mathrm{P}<0.05)$ at $96 \mathrm{hr}$ of exposure with a maximum decline up to $54.47 \%$ at $240 \mathrm{hr}$ of exposure, whereas, in sublethal concentrations an initial increase up to $96 \& 240 \mathrm{hr}$ of exposure followed by a decline from $480 \mathrm{hr}$ onwards. However, the decline $(28.80 \%)$ was found statistically significant $(\mathrm{P}<0.05)$ at $960 \mathrm{hr}$ of exposure to 39.45 $\mathrm{mg} / \mathrm{l}$ concentrations only when compared with that of their normal values.

\section{DISCUSSION}

Increase in opercular beat \& restlessness in toxic environment is characteristic of the fish exposed to hypoxic conditions (Randall \& Shelton, 1963; Shidmore, 1970). Jones (1938) observed a decrease on oxygen uptake and correlated with increase in opercular beat in Gasterosteus aculatus exposed to lethal concentrations of few metallic salts and stated that it was mainly due to reduced efficiency of the gills. Singh \& Singh (1979) in Mystus vittatus exposed to Zinc and copper, Kumari (1990) in H. fossilis exposed to Zinc and Suraj (1998) in Anabas testudineus exposed to cadmium \& cobalt observed an increase in opercular frequency during initial hour of exposures followed by a decrease, more in lethal than sublethal concentrations depended on exposure hours.

In the present study, there is decrease in ventilation rate at higher concentration, but an increase at lower concentrations initially followed by a decrease in later stages of intoxication. The increase in ventilation rate is probably due to an effort to extract more oxygen to fulfill its energy demands to fight the stressful conditions, while decrease in ventilation rate may be due to titanic effect on opercular and branchial muscle caused by cobalt and / or might be due to gill injury or due to disturbances in gas diffusion pathway by abnormal secretion of mucus all over the body surface including gills.

Several workers have reported that metallic salts decreased the oxygen consumption rate of the fish with an increase in concentration and exposure period (David \& Ray, 1966; Calabrese et. al., 1975; Sastry \& Shukla, 1990 and Suraj, 1998) and suggested that such metallic salt causes asphyxiation in fish resulting in reduced $\mathrm{O} 2$ uptake rate. Crandall and Goodnight (1963) have suggested that prolonged exposure of fish to low concentration of heavy metals subjects them to stress which causes hormonal imbalance ultimately leading to a variety of internal pathological changes.

In the present study, an initial increase in oxygen uptake rate up to 8 hours in lethal and 240 hours of exposure in sublethal concentrations followed by a gradual and significant decrease $(\mathrm{P}<0.05)$ at $96 \mathrm{hr}$ with maximum of 54.47 decrease at $240 \mathrm{hr}$ of exposure in lethal and $28.80 \& 10.65 \%$ decrease at 960 hour of exposure in sublethal concentrations observed, indicates that the initial increase on $\mathrm{O} 2$-uptake rate might be due to over activeness of the fish or due to some internal factors (Crandall \& Goodnight, 1969) and the subsequent decrease may be due to injury of the gills and other vital organs and / or also might be due to abnormal secretion of mucus all over the body and gills, obstructing gas diffusion pathway. 


\section{REFERENCES}

[1] Anderson, J. W.; Neff, J. M., cox, B.A.; Tetum, H.E. and Hightower, G.M. 1974: The effects of oil on estuarine animals to toxicity, uptake \& duration. In, "Pollution \& Physiology of marine organisms". (Ed. Veruberg, F. J. \& Veruberg, W.B.), Academic Press INC. New York pp 285-310.

[2] A.P.H.A. 1985: "Standard Methods for Examination of Water and Waste Water." Washington D. C.

[3] Calabrese, A.; Thurberg, F. P.; Dawson, M.A. \& Wenzloff, D. R. 1975: Sublethal physiological stress induced by cadmium and mercury in the winter flounder, Pseudopleuronectes americanus. In. "Sublethaleffect of toxic chemicals on aquatic animals.” (Eds. Koeman, J. H. \& Strike, J. J. T.W.A.) Elsevier, Amsterdam. pp. 15-21.

[4] Crandall, C.A. \& Goodnight, C. J. 1963: The effects of sublethal concentrations of several toxicants to common guppy, Labistes reticulates. Trans. Am. Microse, Soc., 82: 59-73.

[5] David, A. \& ray, P. 1966: Studies on the pollution of the river Daha (North Bihar) by Sugar \& Distillery wastes. Environ. Hlth., 8: 6-35.

[6] Doudoroff, P.; Anderson, B. G.; Burdick, C. E.; Gastoff, P.S.; Hart, W.B.; Patrick, P.; Strong, E.R. surber, F.W. \& Vanltron, W. M. 1951: In, "Environmental pollution by pesticides. " (Ed. Edward, C. A.), Plenum Press, London \& N. Y. pp. 218.

[7] Fry, F. E.J. 1957: The aquatic respiration of fish. In, "The Physiology of Fishes" (Ed. Brown, M. E.) Vol. I, Academic Press London, N. Y.

[8] Fry, F. E.J. 1971: "The effects of environmental factors on the physiology of fish. In, "Fish Physiology", (Eds. Hoar, W. S. \& Randall, D. J.) Vol. VI, Academic Press London, N. Y.

[9] Jones, J.R.E. 1938: The relative toxicity of salts of lead, zinc \& copper to the stickle back, Gasterosteus aculeatus and the effects of calcium on the toxicity of lead, zinc and salts. J. Exp. Biol., 15: 394-407.

[10] Kumar, N. 1999: Effect of few insecticides on air breathing \& water breathing fish. A comparative study, Ph.D. Thesis, B. R. A. Bihar Univ. Muzaffarpur (Bihar) India.

[11] Kumari, R. 1990: Effects of some toxic solutions on the respiration of air-breathing cat fish., H. fossilis (Bloch.) Ph. D. Thesis, B. R. A. Bihar Univ. Muzaffarpur (Bihar) India.

[12] Natrajan, G. M \& Rajulu, G.S. 1983: Effect of sublethal concentrations of metasystox on the circadian rhythm of bimodal oxygen uptake in Channa striatus Curr Sci., 52(14): 675-677.

[13] Randall, D. J. \& Shelton, G. 1963: The effect of changes in environmental gas concentration on the breathing \& heart rate of teleost fish. Comp. Biochem. Physiol., 9: 229-239.
[14] Roy, P. K. \& Munshi, J. S. D. 1988: Oxygen consumption \& Ventilation rate of a freshwater fish, Cirrhinus mrigala(Ham.) in fresh and malathion treated waters. J. Environ. Biol. 9(1): 5-13.

[15] Sastry, K. V. \& Shukla, V. 1990: Toxic effect of cadmium on some biochemical \& physiological parameters in teleost fish, Channa punctatus. Biojournal 2(2):325-332.

[16] Singh, S. R. \& Singh, B. R. 1979: Changes in Oxygen consumption of a siluroid fish, Mystus vittatus put to different concentrations of some heavy metal salts, Ind. J. Exp. Biol., 17:274-276.

[17] Skidmore J. F. 1970: Respiration \& Osmoregulation in rainbow trout with gills damaged by zinc sulphate, J. Exp. Biol., 52: 481-494.

[18] Suraj, 1995: Studies on nutritional requirement of calcium and phosphorus of Indian major carp, Cirrhinus mrigala (Ham.), M.Sc. IFAM, Disser. C. I. F. E., Mumbai, India.

[19] Suraj, 1998: Effect of few metallic salts on the physiological \& biochemical parameters of some freshwater fishes. Ph.D. Thesis, B. R. A. Bihar Univ. Muzaffarpur (Bihar) India. 
Table -1: Ventilation rate /minute and oxygen consumption (VO2: $\mathrm{MlO} / \mathrm{hr}$ and $\mathrm{MlO} / \mathrm{Kg} / \mathrm{hr} /$ fish in Cirrhinus mrigala (Ham.) in relation to lethal and sublethal concentrations of cobalt chloride exposed for different periods at $29.5^{ \pm} 2.70 \mathrm{C}$ water temperature

\begin{tabular}{|c|c|c|c|c|c|c|}
\hline \multirow{2}{*}{$\begin{array}{l}\text { Concent } \\
\text { ration } \\
(\mathrm{mg} / \mathrm{l})\end{array}$} & \multirow{2}{*}{$\begin{array}{l}\text { Exposure } \\
\text { Period } \\
\text { (hr) }\end{array}$} & \multicolumn{2}{|c|}{ Ventilation rate Per Minute } & \multicolumn{3}{|c|}{ Oxygen Consumption rate (VO2) } \\
\hline & & Value & $\%$ Change & $\mathrm{MlO} 2 / \mathrm{hr} / \mathrm{Fish}$ & $\mathrm{MlO} / \mathrm{Kg} / \mathrm{hr} / \mathrm{fish}$ & $\%$ Change \\
\hline Control & 8 & $89^{ \pm} 2$ & & $1.88^{ \pm} 0.13$ & $76.50^{ \pm} 5.34$ & \\
\hline 92.00 & & $83^{ \pm}$ & -6.74 & $2.12^{ \pm_{0.13}}$ & $86.17^{ \pm} 5.08$ & 12.65 \\
\hline 39.45 & & $96^{ \pm} 2$ & 7.86 & $1.96^{ \pm} 0.13$ & $79.84^{ \pm} 4.94$ & 4.36 \\
\hline 13.10 & & $94^{ \pm}$ & 5.62 & $1.85^{ \pm} 0.12$ & $75.20 \pm_{4.65}$ & -1.70 \\
\hline Control & 24 & $87^{ \pm} 1$ & & $2.05^{ \pm} 0.12$ & $83.17^{ \pm} 5.20$ & \\
\hline 92.00 & & $79^{ \pm}{ }_{2 *}$ & -9.19 & $1.68^{ \pm} 0.13$ & $68.25^{ \pm} 4.66$ & -17.94 \\
\hline 39.45 & & $104^{ \pm}{ }_{3 * *}$ & 19.54 & $2.12^{ \pm_{0.12}}$ & $86.18^{ \pm} 4.91$ & 3.62 \\
\hline 13.10 & & $94^{ \pm}{ }_{2 *}$ & 8.04 & $2.16^{ \pm} 0.11$ & $87.97^{ \pm} \pm_{5.23}$ & 5.77 \\
\hline Control & 96 & $89^{ \pm}$ & & $1.97^{ \pm^{ \pm}} 0.12$ & $79.88^{ \pm} 4.85$ & \\
\hline 92.00 & & $70^{ \pm}{ }_{2 * *}$ & -21.35 & $1.21^{ \pm} 0.11^{*}$ & $49.27^{ \pm}{ }_{4.54}$ & -38.32 \\
\hline 39.45 & & $110^{ \pm}{ }_{2 * *}$ & 23.59 & $2.16^{ \pm} 0.13$ & $87.84^{ \pm} \pm_{5.23}$ & 9.27 \\
\hline 13.10 & & $113^{ \pm * *}$ & 26.97 & $2.02^{ \pm} 0.13$ & $82.03^{ \pm} 5.06$ & 2.70 \\
\hline Control & 240 & $86^{ \pm_{3}}$ & & $1.90^{ \pm} 0.12$ & $77.24^{ \pm} 4.69$ & \\
\hline 92.00 & & $62^{ \pm}{ }_{3 * *}$ & -27.91 & $0.87^{ \pm} \stackrel{0.12 *}{*}$ & $35.16^{ \pm} 4.90$ & -54.47 \\
\hline 39.45 & & $99^{ \pm}{ }^{*}$ & 15.12 & $1.98^{ \pm} 0.13$ & $80.49^{ \pm} 5.32$ & 4.21 \\
\hline 13.10 & & $110^{ \pm}{ }_{2 * *}$ & 27.91 & $2.20^{ \pm} 0.13$ & $89.51^{ \pm} 5.14$ & 5.89 \\
\hline Control & 480 & $88^{ \pm}{ }_{2}$ & & $1.95^{ \pm} 0.13$ & $79.06^{ \pm} 5.33$ & \\
\hline 92.00 & & --- & --- & --- & --- & ---- \\
\hline 39.45 & & $79^{ \pm}{ }_{2 *}$ & -10.23 & $1.76^{ \pm} 0.12$ & $71.50 \pm_{4.70}$ & -9.56 \\
\hline 13.10 & & $82^{ \pm}$ & -6.82 & $1.99^{ \pm} 0.13$ & $81.29^{ \pm} 5.02$ & 2.52 \\
\hline Control & 960 & $85^{ \pm} 3$ & & $1.90^{ \pm} 0.13$ & $77.07^{ \pm} 5.10$ & \\
\hline 92.00 & & --- & --- & --- & --- & ---- \\
\hline 39.45 & & $64^{ \pm}{ }_{3 * *}$ & -24.70 & $1.35^{ \pm} 0.11^{*}$ & $54.88^{ \pm_{4.63}}$ & -28.80 \\
\hline 13.10 & & $74^{ \pm}{ }^{ \pm}$ & -12.94 & $1.69^{ \pm} 0.14$ & $68.85^{ \pm} 5.25$ & -10.65 \\
\hline$\pm_{\text {is st }}$ & & 5 observa & & $\sigma^{\prime * *} "=\mathbf{P}<0.05$ & ( & $<0.01$ \\
\hline
\end{tabular}

